\title{
CAVALCANTI, Maria Laura (org.). 2014. Ritual e Performance: 4 estudos clássicos. Rio de Janeiro: 7 Letras. 122 pp.
}

\author{
GABRIEL BERTOLO
}

Ao lermos os artigos selecionados por Maria Laura Cavalcanti não restam dúvidas: o estilo da escrita dos textos traduzidos, as descrições rigorosas, o nível de detalhamento nas descrições das festas, rituais, danças e música - isto é, das performances, tema central deste livro - "nos levam" direto ao Reino Unido do começo do século XX. Mais precisamente ao ambiente acadêmico onde era praticada e teorizada uma antropologia que viria a ser conhecida pela alcunha de estrutural-funcionalismo. Como bem lembra a autora em sua introdução, tal "escola" tem Radcliffe-Brown e Malinowski como suas figuras mais celebradas e estudadas nos cursos de graduação em Ciências Sociais e cursos de pós-graduação de antropologia brasileira. No entanto, isto acabou por relegar seus colegas e "discípulos", junto com seus debates, aos especialistas do tema.

Nesse sentido, o livro organizado por Cavalcanti, com traduções de Igor Mello Diniz e da própria organizadora, é um trabalho necessário e uma lufada de ar fresco para os interessados. Com textos de Evans-Pritchard, Meyer Fortes, Hilda Kuper e Monica Wilson, a coletânea preenche competentemente uma lacuna, deixada não apenas pela até então indisponibilidade em português destes textos, mas também pela própria "canonização" das figuras citadas acima: uma espécie de redução dessa escola de pensamento antropológico aos seus maiores ícones. Com a consequente redução dos temas, problemas, tópicos àqueles discutidos por Radcliffe-Brown e Malinowski. Embora Evans-Pritchard e Meyer Fortes não sejam "desconhecidos" da antropologia brasileira, certamente os textos apresentados causam impacto. Não apenas por seu ineditismo, mas pelo próprio conteúdo e discussões oferecidas, que nos serve como uma válvula de escape dos clichês a que estamos acostumados quando pensamos estrutural-funcionalismo, especialmente para os não especialistas no assunto.

O artigo que abre o livro é de autoria de Evans-Pritchard, intitulado "A Dança" (ano original 1928) onde analisa uma dança ritual Azande, a gbere buda (dança da cerveja). Aqui, o autor faz mais que apenas ressaltar o papel dessa dança como fator de equilíbrio social. Sua análise parte, como sempre, de detalhados exemplos etnográficos, classificados por ele em seus diferentes aspectos. Assim, no que poderia ser considerado um exercício de etnomusicologia, o autor perpassa elementos que compõe a gbere buda, sem os quais não seria possível compreendê-la. São três estes elementos, que por sua vez 
são reclassificados em distinções menores: a música, o canto e o movimento. O que é notável aqui é que em nenhum momento essas distinções e classificações são "apenas" funções sociais. Elas são funções da dança, e de certa maneira, há neste texto, uma espécie de modelo para um estudo da dança mais completo, inserido dentro de um contexto social mais específico. Ora, é simbólico nesse sentido que a todo momento o autor lamente não ter a sua disposição (mais) gravações cinematográficas e audiográficas, pois o que buscava não eram somente as funções e significados sociais dessa dança, mas antes, um estudo da dança mais completo. $\mathrm{O}$ que porventura incluiria tais significados e funções sociais. Desse modo, o significado social da dança como ritual é “apenas" um dos aspectos que nos ajudam a entender o que seriam as próprias noções de ritual e de performance, em sentido mais amplificado. Ou, melhor dizendo, de uma performance ritual em um sentido mais abrangente.

Para a compreensão do que seria propriamente ritual nesta dança Azande, Evans-Pritchard ressalta não o potencial agregativo, o equilíbrio social firmado pela dança (embora não o negue) mas aqueles aspectos que rompem, por assim dizer, a ordem e o equilíbrio. Ele nos dá exemplos etnográficos de como em meio a dança ritual (sua análise restringe-se ao gbere buda realizado por ocasião de festas funerárias), algumas das atitudes de seus participantes não condiziam com a atitude ritual apropriada para aquele momento (embora não o fossem exatamente "não rituais"). Assim, ele fala de como, por exemplo as disputas sexuais envolvidas nos rituais poderiam gerar uma disrupção no próprio ritual ( $\mathrm{p}$. 29) e de como o consumo de cerveja poderia exaltar os participantes em disputas e intrigas que não tinham "nada" a ver com o evento, mas que são parte integrante do ritual e, a seu modo, um outro jeito de garantir a coesão (p. 35-36).

Temos aqui uma crítica à noção de equilíbrio como formulada por Radcliffe-Brown, na medida em que esta noção aparece na obra deste autor como um elemento dado: para Evans-Pritchard, são necessários mecanismos sociais tão poderosos como a feitiçaria ou uma liderança na dança, para que a coesão e o equilíbrio se efetuem. Esta "força de coesão", não existe por si só, não é um dado exterior aos grupos sociais. Nas palavras de Evans-Pritchard, "é preciso salientar que, apesar de a dança gerar um sentimento de camaradagem geral, tais ocasióes produzem não obstante perigos disruptivos para a unidade e a concórdia festivas [...] e tentamos mostrar que há maquinaria social para impedir essas desordens" (p. 35, grifos meus). É nessa maquinaria social, que é feita de feitiçaria, de dança, de sexo e de brigas, por exemplo, que a coesão social é feita pelos próprios performers e indivíduos de uma sociedade. Algo que problematiza a formulação ex-nibilo de coesão social como mecanismo social básico no sentido clássico de inspiração durkheimiana do modelo proposto pela escola de Radcliffe-Brown. De certo modo, o sentido e invertido já aqui, em Evans-Pritchard; se podemos falar de coesão social e porque ela é produzida pelo corpo social e não o contrário.

De maneira similar, Meyer Fortes (1936) pontua que nos territórios da Costa do Ouro, atual Gana, entre os Tallensi, coesão social é algo justamente não evidente. Sua crítica é, de partida, mais direta, por assim dizer, chegando a comentar que, naquele período, "coesão social ganhou lugar de honra na literatura antropológica como um dispositivo poupador de trabalho". Este conceito de coesão social era tratado como "autoevidente, uma primeira lei da vida social como a primeira lei do movimento de Newton, pela qual tudo o mais poderia ser explicado" (p. 39). 
Deste modo, Fortes empenha-se em demonstrar como na verdade este conceito só faz sentido quando observado sob a luz de elementos que a primeira vista nos dizem o contrário, isto é, de elementos de desiquilíbrio e das diferenças entre Tallis e Namoos, os dois grupos cultural e politicamente distintos que compõe o povo Tallensi.

Através de uma série de contrastes entre estas duas populações, reside o ponto chave para a leitura do autor, à medida que, de acordo com as análises feitas à época, eles formariam apenas um povo, os Tallensi. Sua análise parte de contrastes rituais, especialmente sobre proibições diferenciadas de certos cânticos, danças e feitiços entre Tallis e Namoos. A partir do que seria proibido para os Tallis e permitido aos Namoos, e vice-versa, Meyer Fortes observa uma espécie de complementaridade entre ritual e cultura e entre os dois grupos. Mas não apenas no estilo clássico do entendimento da coesão social que o próprio autor está criticando. Essa complementaridade só pode existir a partir da diferenciação política que ela proporciona e seu consequente equilíbrio.

De acordo com o autor, embora os dois povos se apresentem como uma cultura unificada, eles são politicamente distintos e apresentam formas de festividades diferentes devido a esse mesmo fator. Segundo Fortes:

"Por um lado, écomo se cada comunidade se consolidasse social e moralmente pelo simples fato de rejei-
tar seus vizinhos [...] A diferença entre os ritos dos Tallis das Colinas e aqueles dos Namoos demonstra
exemplarmente a dicotomia e o antagonismo dessa polaridade fundamental para a estrutura política
dos Tallensi. Está certo que toda atividade cerimonial tale expressa a exclusividade do grupo que a
realiza, mas, nesses festivais, a expressão da diferença só tem validade política porque é reciproca. A
diferença é tornada pública na dança e dramatizada no ritual esotérico". (p. 54)

Meyer Fortes, em seguida, questiona como Tallis e Namoos, através dessas diferenças, se apresentam como "comunidades culturalmente equivalentes" e muito íntimas econômica e socialmente; como, afinal, apresentam um "idioma cultural comum, além de uma única língua" (p. 41). Se é na diferença ritual que ele encontra a chave para a distinção política entre os dois grupos, é na própria oposição política que ele encontra a resposta para esta questão.

Isto é, seu questionamento é sobre como surgem os Tallensi como cultura "unificada", como sociedade (ou grupo social). É a própria intimidade entre Tallis e Namoos, esclarece o autor, que estabelece um limite à diferenciação entre os dois grupos, e é a partir do próprio limite de diferenciação que gera-se uma dependência mútua.

Colocando o que descreve o autor de maneira resumida: em seu denso relato etnográfico sobre os rituais de chefia entre Namoos e Tallis, posições políticas diferenciadas entre os dois grupos - Naam e Tendaana, respectivamente - são constituídas por uma série de tabus entre as duas lideranças (e entre as lideranças das subdivisões clânicas entre dos dois grupos), todas elas refletidas nos cerimoniais e nas próprias relações econômicas entre Namoos e Tallis. Não obstante, quando entra o mês do Golib, um festival realizado como meio de assegurar o sucesso do plantio, da colheita e da fertilidade em geral, Nesse festival são distribuídos cargos e aparatos sagrados entre os clãs dos Tallis, marcado por diversas 
restrições, como a de derramamento de sangue, uso de roupas de pano, escolha de uma esposa e até mesmo ritos funerários, que são adiados.

Durante esse festival, os Namoos são excluídos do ritual principal, podendo apenas participar como expectadores de algumas danças, sendo até mesmo vetado a um Namoo ver um desses rituais. Mas o ritual final requer uma reintegração entre os dois grupos. Os chefes dos dois grupos têm de cooperar para que o ritual seja bem-sucedido, e Fortes enxerga nessa cooperação a evidência de que "as funções sociais integrativas estão determinadas primordialmente pelo contexto da estrutura social, e evidenciam-se nas cerimônias peculiares da ocasião" (p. 56).

E, concluindo seu raciocínio, o autor, de maneira similar a Evans-Pritchard, afirma: "o conceito de coesão social como eu o entendo, tanto no interior das duas grandes comunidades da sociedade tale, quanto entre elas, não é um atributo último dessa sociedade, mas é antes o resultado da ação de mecanismos sociais específicos" (p. 57). São esses mecanismos sociais específicos de diferenciação que, na leitura de Fortes, quando opostos um ao outro, são os responsáveis por gerar a coesão, e não o contrário. Aqui também há a noção de que a famigerada coesão também é feita, ela é criada no "interior" das relações sociais e não uma imposição de uma sociedade transcendental, um "atributo último" da sociedade que se impõe sobre essas mesmas relações.

O texto de Hilda Kuper (1944), "Um Ritual de Realeza entre os Suazi”, encontra-se um registro diferente dos demais (bem como o de Monica Wilson). Seu texto foca na descrição do ritual Incwala, apresentado como evento de confirmação de poder do rei Suazi. O texto é marcante precisamente por nos lembrar de um estilo etnográfico que talvez tenha se perdido entre os rituais acadêmicos textuais contemporâneos. Trata-se de uma descrição que, além de elaborar análises sobre as significações sociais e sobre a estratificação social dos Suazi, preocupações do estrutural-funcionalismo, apresenta um estilo diferente, precisamente por encontrar-se em um espaço-tempo diferente daquele em que se inserem etnógrafos homens, como discutido por Christine Hugh-Jones em sua seminal etnografia entre os Pirá-Paraná (From the Milk River: Spatial and Temporal Processes in Northwest Amazonia, 1979); a descrição de Kuper sobre o Incwala, justamente pela firmeza e detalhamento da descrição, caminha no mesmo sentido dos textos anteriores, embora por vias diferentes, e mostra o quanto a coesão social, em vez de imposta "de fora para dentro" é talhada no próprio cotidiano das relações rituais.

Como seu registro encontra-se neste espaço-tempo que é convencionalmente chamado de doméstico, no que também se convencionou como uma "periferia política”, um espaço-tempo tido como menos importante e impactante na constituição do aspecto ritual, creio que o relato etnográfico de Kuper possa nos guiar por um estilo etnográfico que captura os aspectos rituais nas malhas do cotidiano. Deste modo, sua visão pode nos ajudar a repensar a noção do ritual como algo apartado desse domínio "doméstico", o que, segundo algumas das teorias mais aceitas durante um longo tempo na antropologia, diferencia o aspecto ritual.

Em sua análise, Kuper mostra precisamente o quanto de cotidiano existe na produção e reprodução de um ritual, o que é mais marcante por se tratar de um ritual excepcional realizado apenas quando um rei assume o poder ou atinge a maioridade (do contrário, a Incwala é suspensa). Na seção reservada aos preparativos da festa-ritual, e nos relatos de menores proporções, realizados como pre- 
parativos, podemos ver como o que marca o ritual como algo apartado das malhas do cotidiano é um outro cotidiano; marcadamente ritual, circunscrito por regras diferentes, mas ainda, cotidiano. Como, por exemplo, no caso dos jovens que devem buscar galhos de árvores lusekwane (p. 76) ou o preparo dos medicamentos que devem ser ingeridos pelo rei quando a Incwala acontecer.

Ora, é a partir mesmo dessas relações que a autora (re)constrói a ideia de coesão; ou seja, podemos entrever aqui uma linha que percorre o livro inteiro, cada texto a seu modo; trata-se de um questionamento vivo de como se constituem essas sociedades, esses agrupamentos, esses rituais, e não tomá-los como dados, garantidos por uma espécie de "ordem" superior, como se as sociedades, rituais, grupos, etc., fossem entidades mágicas que preexistem às relações sociais. São a partir dessas mesmas relações que se formam essas "instituições". O ponto de vista de Kuper sobrescreve de maneira forte essa afirmação, ao trazer para o centro da análise do ritual aquilo que é tipo como lateral, periférico e às vezes até desimportante.

Nesse aspecto, a análise de Monica Wilson, "Ritual e simbolismo entre os nyakyusa", de 1954, também segue a mesma linha, com o adendo de apontar na metáfora e no próprio simbolismo nyakyusa esses aspectos outrora marginais. Mais que isso, a autora a todo momento, ressalta a significação do poder de criação ritual nyakyusa. Ora, se Wilson está aqui ressaltando o poder de criação do e no ritual entre os Nyakyusa, e se o ritual é, para autora, o elemento constituinte da coesão social, mais uma vez, a coesão só pode ser criada pelos participantes deste ritual. Mas não por uma necessidade intrínseca de criação da coesão, mas antes como resultado de outras relações sociais. Um exemplo analítico da autora esclarecerá este dado.

Em meio a discussões sobre os significados sociais da festa e do ritual nyakyusa, chegando mesmo a debater o que seria o próprio simbolismo social, uma dessas discussões chama a atenção, sendo essa baseada na própria concepção nyakyusa sobre seu ritual. Isto ocorre no momento em que Wilson discute a natureza do simbolismo ritual nyakyusa e estabelece uma analogia com o simbolismo da poesia. Suas preocupações giram em torno de como o simbolismo produz seus signos de diferença e semelhança. Nesse sentido, a autora faz uma distinção entre o simbolismo poético e o simbolismo ritual: ao passo que as associações simbólicas necessitam de um "idioma cultural, formas aceitas de expressão" - e por isso o simbolismo poético é idêntico ao ritual - no simbolismo ritual as coisas que se assemelham são colocadas em uma relação de causalidade, ao contrário da poesia em que "elas são apenas similares e isso é tudo". Diferente da poesia, em que as associações são apenas semelhanças simbólicas, nos rituais nyakyusa, essas semelhanças têm efeitos reais; mas o essencial é que:

O semelhante produz o semelhante [...] e, às vezes, as coisas ou ações semelhantes são tidas como antagônicas [...]. No campo da antropologia, não creio que haja quaisquer regras, quaisquer princípios gerais a serem encontrados, que explicariam por que algumas coisas são escolbidas como simpáticas e outras antagônicas, ou mesmo por que certas coisas são escolhidas como assemelhadas. Isso depende do que o poeta sentiu quando criou sua imagem, pois o adivinho e o médico que criam um novo ritual ao modificar o antigo, são nesse sentido, poetas (p. 116). 
O trecho acima talvez resuma precisamente o argumento geral do livro. Não se trata, como na crítica de Fortes, de simplesmente enxergar a coesão social à força nos contextos observados; trata-se, antes, de um trabalho árduo de descrição que visa compreender os mecanismos básicos pelos quais essa coesão se forma e de como, no limite, se cria a própria sociedade que deveria ser "coesa". São preocupações teóricas e metodológicas (que, no entanto, se dobram sobre o campo político-epistemológico de nossa disciplina) de uma antropologia atual, sobre como se criam e se recriam grupos sociais e os modelos de compreensão sobre estes mesmos grupos sociais. Nas palavras da própria organizadora: "Com eles podemos transcender a leitura mais mecânica das conceituaçôes canônicas do estrutural-funcionalismo, que, despojando-as de conteúdo etnográfico e das formulaçóes mais criativas e heterodoxas, tendem a ver no ritual apenas um reforço das normas e a expressão de conflitos" (p. 11) que reforçam a coesão social. O tema aqui é outro: criatividade social.

Gabriel Bertolo é doutorando no PPGAS da UFSCar.

RECEBIDO: $02 / 03 / 2017$

APROVADO: $10 / 07 / 2017$ 